\title{
PLANO NACIONAL DE EDUCAÇÃO: USO DAS TECNOLOGIAS NO ENSINO MÉDIO
}

\author{
Pedro Pereira Cortes Filho ${ }^{1}$ \\ Daniel Barbosa dos Santos ${ }^{2}$ \\ Patrícia da Cruz Dias ${ }^{3}$
}

RESUMO: O presente artigo visa analisar o Plano Nacional de Educação (PNE) na perspectiva das metas que relacionam o uso das tecnologias na educação. Tendo em vista que as tecnologias de informação e comunicação estão cada vez mais presentes na sociedade atual, a educação não pode estar excluída desse processo. Assim, faz-se necessário que as estratégias de conhecimento utilizadas pelas escolas considerem o uso das tecnologias contempladas tanto no PNE quanto no Plano Estadual de Educação do Tocantins (PEE/TO). Dessa maneira, com um olhar para as juventudes e tendo como público os alunos do ensino médio, buscou-se verificar se as metas propostas no PNE em relação às tecnologias na educação, no Tocantins, estão sendo cumpridas, estão em andamento ou estão na perspectiva de cumprimento.

Palavras-chave: Plano Nacional de Educação. Tecnologia. Juventude(s) e Ensino médio.

RESUME: This article aims to analyze the National Education Plan (PNE) from the perspective of the goals that relate the use of technologies in education. Considering that information and communication technologies are increasingly present in today's society, education cannot be excluded from this process. Thus, it is necessary that the knowledge strategies used by schools consider the use of technologies contemplated both in the PNE

\footnotetext{
I Mestrado Profissional em Educação pela Universidade Federal do Tocantins - UFT (2020/cursando). Graduação em Licenciatura Plena em Matemática pela Universidade Estadual do Tocantins - UNITINS (200I). Especialização em Metodologias Inovadoras Aplicadas à Educação na área específica de Matemática, Ciências e suas Tecnologias pela FACINTER de Curitiba-PR (2006). Especialização em Avaliação Escolar em Matemática pela Fundação CESGRANRIO/RJ (2009). Professor de Matemática efetivo do Instituto Federal de Educação, Ciência e Tecnologia do Tocantins (2019 aos dias atuais). ID Lattes: 2902971521026851.Email: pedro.cortes@mail.uft.edu.br.

${ }^{2}$ Mestrado Profissional em Educação-UTF (mestrando 2020). Possui graduação em Serviço Social pela FUNDAÇÃO UNIVERSIDADE DO TOCANTINS -UNITINS (2012). Pós -Graduado Gestão Serviço Social e Políticas Públicas pela Faculdade ITOP (2014), Pós-Graduado em Economia Solidária (UFT) (2016), experiência na área da Educação, Serviço Social, com ênfase em políticas Sociais, Políticas públicas, com acúmulo de experiências nos seguintes temas: Educação, Educação, do campo, Questão Agraria, Meio Ambiente, Economia Solidária, Cooperativismos, Agricultura Familiar, Profo do Curso de Graduação em Serviço Social na UNIP e Faculdade ITOP (atualmente). E-mail: barbosa.daniel@mail.uft.edu.br

3 Professora de Geografia da Rede Estadual de Ensino do Tocantins. Formada em Licenciatura Plena em Geografia pela Universidade Federal do Tocantins. Formada em Licenciatura Plena em Pedagogia pela Faculdade de Filosofia, Ciências e Letras De Boa Esperança. Especialização em Ensino de Geografia pela Faculdade de Patrocínio. ID lattes: 616453693160047ı. E-mail: patriciadacruzdias@hotmail.com.
} 
and in the State Education Plan of Tocantins (PEE/TO). Thus, with a view to youth and having high school students as an audience, we sought to verify whether the goals proposed in the PNE in relation to technologies in education, in Tocantins, are being met, are in progress or are in perspective of compliance.

Keywords: National Education Plan. Technology. Youth (s) and High School.

\section{INTRODUÇÃO}

Estamos passando por momento de grave crise sanitária que requer cuidado e atenção de todos. Essa pandemia, causada pelo coronavírus, tem tirado vidas e provocado verdadeiras transformações no dia a dia, demandando adaptações no modo de conviver e trabalhar, nos mais variados setores de nossa sociedade. Na educação não é diferente. Estamos presenciando e compartilhando uma nova forma de ensinar e aprender, respeitando o distanciamento social e fazendo uso das tecnologias. Professores e alunos precisaram se atualizar, adaptando-se para que o trabalho fluísse com o ensino remoto, que hoje é uma realidade. Assim, as tecnologias são essenciais, encurtando distâncias e possibilitando, mesmo que não ainda na sua totalidade, a inclusão e interação de alunos e professores ao sistema educacional. Fazendo com que o ensinar e o aprender continuassem a fluir, e consequentemente reduzindo os 'prejuízos' aos estudantes.

Portanto, é importante analisar como estão sendo aplicadas, pensadas e desenvolvidas as metas do Plano Nacional de Educação (PNE) relacionadas ao uso das tecnologias na educação. Afinal, o presente e certamente o futuro da educação passam e passarão a conviver mais com as tecnologias. Portanto, as práticas pedagógicas e o ambiente escolar devem considerar essa realidade.

Nesse sentido, entende-se por PNE como o aperfeiçoamento científico e democrático da educação e, para compreendê-lo, precisamos centrar as análises na confluência entre suas metas e estratégias. Julga-se indispensável e significativo iniciar uma discussão teórica sobre o tema. Embora a questão não seja nova nos estudos em educação, propõe-se que seja retomada e ressignificada a partir das circunstâncias no atual momento histórico, social, político, econômico que estamos vivenciando. Sendo assim, é importante destacar também o Plano Estadual de Educação (PEE), que tem por objetivo conduzir as políticas públicas de educação à realidade do Estado do Tocantins, buscando estabelecer prioridades, diretrizes, objetivos e metas básicas, e avançar para uma educação de qualidade.

O principal objetivo deste artigo é levantar dados e analisar o desenvolvimento das metas e estratégias do PNE (2014-2024) relacionadas ao uso das tecnologias, fazendo referência às juventudes que compõem o Ensino Médio em escolas públicas no estado do Tocantins. Para isso, além das pesquisas documental e bibliográfica, foram aplicados questionários a três diretores de três escolas tocantinenses, a fim de verificar o andamento e a execução, as perspectivas e dificuldades, bem como o que as escolas tem feito diante do cenário atual em relação ao cumprimento dessas metas.

O despertar para a pesquisa e o aprofundamento dessa temática se deram a partir dos estudos realizados na disciplina Juvenilização da Educação de Jovens e Adultos do Mestrado Profissional em Educação. Nela, foram abordados conceitos acerca de juventudes e tecnologias educacionais, o que despertou o interesse destes pesquisadores para uma análise mais detalhada quanto ao cumprimento, o andamento e a execução das 
metas do PNE no Tocantins, em particular, aquelas que possuem como estratégias o uso das tecnologias.

\section{Plano Nacional de Educação (PNE)}

De acordo com o próprio documento do PNE (2014), a primeira versão do Plano Nacional de Educação foi instituída pela Lei $\mathrm{n}^{\circ}{ }^{\circ}$ Io.172, de 9 de janeiro de 20oI, onde vigorou entre os anos de 2001 a 2010. Segundo a Exposição de Motivos (EM) no 33, de 2010, que acompanhou a proposta do Executivo para o PNE 2014-2024, o PNE 200I-20I0 contribuiu para a construção de políticas e programas voltados à melhoria da educação, muito embora tenha vindo desacompanhado dos instrumentos executivos para consecução das metas por ele estabelecidas. A mesma ME critica o PNE 2001-2010 por sua estrutura baseada no tripé "diagnóstico-diretrizes-metas", na medida em que as metas vinham desacompanhadas das estratégias necessárias para seu cumprimento (BRASIL, 2014, p.I4-I5). Aprovado pela Lei no 13.005/2014, "o debate do segundo PNE assemelhou-se menos ao do primeiro PNE e mais ao processo de discussão do Fundo de Manutenção e Desenvolvimento da Educação Básica e de Valorização dos Profissionais da Educação (Fundeb)" (BRASIL, 20I4, p. 17). O documento salienta que sua aprovação representou uma vitória da sociedade brasileira, porque legitimou o investimento de I0\% do PIB em educação e adotou o custo-alunoqualidade. Este mesmo documento em suas considerações, afirma que:

\footnotetext{
A Meta 20 existe para garantir todas as outras metas que trazem as perspectivas de avanço para a educação brasileira, nas dimensões da universalização e ampliação do acesso, qualidade e equidade em todos os níveis e etapas da educação básica, e à luz de diretrizes como a superação das desigualdades, valorização dos profissionais da educação e gestão democrática. (BRASIL, 2014, p. 23).
}

O PNE foi refeito visando o alcance e cumprimento de suas metas, objetivando, assim, através de suas estratégias, fazer com que houvessem melhores resultados na educação brasileira. Com suas diretrizes revisadas, o Plano Nacional de Educação (PNE) foi aprovado pela Lei no $13.005 / 2014$. Trata-se de uma lei ordinária, composta por 14 artigos, com vigência de io anos a partir da data de sua publicação: 26 de junho de 20I4. Portanto, as 20 metas e 254 estratégias, por ela determinadas, devem ser cumpridas até 2024 .

$\mathrm{O}$ artigo 214 da Constituição Federal Brasileira, estabelece o Plano Nacional de Educação, definindo-o como de duração plurianual, cujo objetivo primordial versa sobre a articulação e o desenvolvimento do ensino em seus diversos níveis, integrando as ações do poder público com o foco nas seguintes diretrizes: "a erradicação do analfabetismo, a universalização do atendimento escolar, a melhoria da qualidade do ensino, a formação para o trabalho e a promoção humanística, científica e tecnológica do País” (BRASIL, 1988). Essa conquista trouxe visibilidade e o estabelecimento do PNE, que normatiza a educação brasileira.

O atual Plano Nacional de Educação no Artigo 2º-, apresenta como diretrizes:

I - erradicação do analfabetismo; II - universalização do atendimento escolar; III- superação das desigualdades educacionais, com ênfase na promoção da cidadania e na erradicação de todas as formas de discriminação; IV - melhoria da qualidade da educação - formação para o trabalho e para a cidadania, com ênfase nos valores morais e éticos em que se fundamenta a sociedade; VI - promoção do princípio da gestão democrática da educação pública; VII - promoção 
humanística, científica, cultural e tecnologia do País; VIII - estabelecimento de meta de aplicação de recursos públicos em educação como proporção do Produto Interno Bruto - PIB, que assegure atendimento às necessidades de expansão, com padrão de qualidade e equidade; IX - valorização dos (as) profissionais da educação; X - promoção dos princípios do respeito aos direitos humanos, à diversidade e à sustentabilidade socioambiental (BRASIL, 2014, p.43).

Dessa maneira, as diretrizes gerais mencionadas nos incisos I, II e IV do PNE reafirmam as orientações estabelecidas na Constituição Federal de 1988. No entanto, a diretriz que explicita "formação para o trabalho e a promoção humanística, científica, cultural e tecnológica do País" estão detalhadas nos incisos V e VII.

No PNE constam questões gerais como: as diretrizes, as formas de monitoramento e avaliação, a importância do trabalho articulado entre as diferentes esferas governamentais, a participação da sociedade, os prazos para a elaboração ou adequação dos planos subnacionais e para a instituição do Sistema Nacional de Educação, além dos recursos financeiros à sua implementação. No aparato do plano, delimitam-se ainda as metas e suas respectivas estratégias, conforme anteriormente mencionado. Em consonância com o PNE e o PEE, fica a cargo de cada município a elaboração do Plano Municipal de Educação (PME).

\section{Educação e Tecnologias}

As tecnologias da informação e da comunicação representam novas possibilidades para educação. Sendo assim, é necessário refletir sobre a renovação das práticas pedagógicas e a inclusão das tecnologias no cotidiano das escolas, dos professores e alunos. Nesse sentido, o PNE apresenta as metas e estratégias de cunho tecnológico para o ensino médio, primeiramente apontando as metas para o público desejado, para então desdobrar as estratégias com o direcionamento às tecnologias.

De acordo com PNE as metas 7, 8, ro e II, visam garantir o acesso dos alunos do ensino médio ao sistema tecnológico que permite as seguintes ações:

Meta7: fomentar a qualidade da educação básica em todas as etapas e modalidades, com melhoria do fluxo escolar e da aprendizagem de modo a atingir as seguintes médias nacionais para o Ideb: Meta 8: elevar a escolaridade média da população de dezoito a vinte e nove anos, de modo a alcançar, no mínimo, doze anos de estudo no último ano de vigência deste Plano, para as populações do campo, da região de menor escolaridade no país e dos vinte e cinco por cento mais pobres, e igualar a escolaridade média entre negros e não negros declarados à Fundação Instituto Brasileiro de Geografia e Estatística (IBGE). Meta ro: oferecer, no mínimo, $25 \%$ das matrículas de educação de jovens e adultos, nos ensinos fundamental e médio, na forma integrada à educação profissional. Meta II: triplicar as matrículas da educação profissional técnica de nível médio, assegurando a qualidade da oferta e pelo menos cinquenta por cento da expansão no segmento público. (BRASIL, PNE 2014).

Assim, potencializando essas ações dentro do PNE, é possível vislumbrar a educação tendo a tecnologia como uma ferramenta do ensino, tornando-se também um atrativo para os jovens. As estratégias para essas metas direcionam os trabalhos: 
7.12. incentivar o desenvolvimento, selecionar, certificar e divulgar tecnologias educacionais para a educação infantil, o ensino fundamental e o ensino médio e incentivar práticas pedagógicas inovadoras que assegurem a melhoria do fluxo escolar e a aprendizagem, assegurada a diversidade de métodos e propostas pedagógicas, com preferência para softwares livres e recursos educacionais abertos, bem como o acompanhamento dos resultados nos sistemas de ensino em que forem aplicadas; em que forem aplicadas; 7.15. universalizar, até o quinto ano de vigência deste $\mathrm{PNE}$, o acesso à rede mundial de computadores em banda larga de alta velocidade e triplicar, até o final da década, a relação computador/aluno(a) nas escolas da rede pública de educação básica, promovendo a utilização pedagógica das tecnologias da informação e da comunicação; 7.20. prover equipamentos e recursos tecnológicos digitais para a utilização pedagógica no ambiente escolar a todas as escolas públicas da educação básica, criando, inclusive, mecanismos para implementação das condições necessárias para a universalização das bibliotecas nas instituições educacionais, com acesso a redes digitais de computadores, inclusive a internet; 8.r. institucionalizar programas e desenvolver tecnologias para correção de fluxo, para acompanhamento pedagógico individualizado e para recuperação e progressão parcial, bem como priorizar estudantes com rendimento escolar defasado, considerando as especificidades dos segmentos populacionais considerados;io.6. estimular a diversificação curricular da educação de jovens e adultos, articulando a formação básica e a preparação para o mundo do trabalho e estabelecendo inter-relações entre teoria e prática, nos eixos da ciência, do trabalho, da tecnologia e da cultura e cidadania, de forma a organizar o tempo e o espaço pedagógicos adequados às características desses alunos e alunas; Ir.I. expandir as matrículas de educação profissional técnica de nível médio na Rede Federal de Educação Profissional, Científica e Tecnológica, levando em consideração a responsabilidade dos institutos na ordenação territorial, sua vinculação com arranjos produtivos, sociais e culturais locais e regionais, bem como a interiorização da educação profissional; II.II. elevar gradualmente a taxa de conclusão média dos cursos técnicos de nível médio na Rede Federal de Educação Profissional, Científica e Tecnológica para noventa por cento e elevar, nos cursos presenciais, a relação de alunos(as) por professor para vinte. (BRASIL, PNE 2014).

Para efetivar suas ações na educação, cada estado, observadas as metas do PNE, elabora o PEE, também com duração de dez anos (2015-2025), com metas e estratégias específicas. Nele, igualmente consta o uso das tecnologias no processo educacional. Podemos citar, por exemplo, as metas 4 e 5 do PEE/TO:

Meta 4: Universalizar, até o segundo ano de vigência deste PEE/TO, o atendimento escolar para toda a população de Is (quinze) a I7 (dezessete) anos de idade e elevar, até o final da vigência deste PEE/TO, a taxa líquida de matrículas no ensino médio para $85 \%$ (oitenta e cinco por cento). Meta 5: Oferecer educação em tempo integral em, no mínimo, 50\% (cinquenta por cento) das escolas públicas, de forma a atender, pelo menos, $25 \%$ (vinte e cinco por cento) dos(as) alunos(as) da educação básica. (SEDUC/TO, 2015)

Observa-se que o PEE procurou fazer adequações à sua realidade, reforçando o acesso e a utilização da tecnologia na educação, conforme estratégias apresentadas para a meta 4:

4.I. Institucionalizar, a partir do segundo ano de vigência deste PEE/TO, as diretrizes estaduais para o ensino médio, em conformidade com as Diretrizes Curriculares Nacionais do Ensino Médio - DCNEM, a proposta nacional de 


\begin{abstract}
direitos e objetivos da aprendizagem e desenvolvimento, e o plano de desenvolvimento do Estado como estratégias educacionais e de atendimento às demandas sociais, regionais, históricas, econômicas, ambientais e culturais dos sujeitos e territórios; 4.2. revisar a proposta curricular e implantar, até o final do terceiro ano de vigência deste $\mathrm{PEE} / \mathrm{TO}$, o referencial curricular do ensino médio, com a participação de professores(as) regentes e gestores(as) da Seduc/TO, em parceria com as instituições de ensino superior, Agência Tocantinense de Ciência Tecnologia e Inovação e Secretaria de Cultura, tendo como base as DCNEM, contemplando a identidade cultural e as especificidades da educação escolar para as populações do campo, povos indígenas e comunidades quilombolas, assegurada a perspectiva inclusiva e a educação integral humanizada. (SEDUT/TO, 2015).
\end{abstract}

$\mathrm{Na}$ estratégia 5.2, observa-se uma preocupação com as estruturas físicas das escolas, com foco na oferta de uma educação de qualidade e utilização de tecnologias:

\begin{abstract}
5.2. instituir, em regime de colaboração com a União e os Municípios, programa para melhoria da estrutura física das unidades escolares, e a construção e manutenção de 13 (treze) escolas públicas estaduais, conforme a demanda, com padrão de qualidade que assegure: a) espaços e estruturas físicas/arquitetônicas, interagindo com o meio físico, geográfico e social, com ambientes articulados e integrados, garantindo estruturas físicas adequadas com acessibilidade, sistemas de eficiência energética, hidráulica e sanitária, priorizando o conforto térmico com climatização e iluminação, minimizando os impactos ambientais; b) utilização e manutenção de tecnologias construtivas e adequadas; c) mobiliários, equipamentos e utensílios adequados, com manutenção periódica, prioritariamente, em comunidades pobres ou com crianças e jovens em situação de vulnerabilidade; d) construção de alojamentos em escolas do campo, indígenas e quilombolas para atender os(as) profissionais da educação de outras localidades. (SEDUC/TO, 2015)
\end{abstract}

No âmbito das etapas da educação básica, na vinculação dos planos constam também objetivos que visam assegurar a participação da comunidade na organização da escola, além de qualificar e quantificar o ensino e suas modalidades. Nesse contexto, é possível relacionar o ensino médio com uma classe juvenil, onde esses grupos se identificam com seus trajes, comportamentos, pensamentos e maneiras de se relacionar socialmente.

\title{
Juventude (s)
}

A juventude desenvolve organismo que contribui com o desenvolvimento do indivíduo e suas habilidades, a educação e o envolvimento social fazem parte desse processo independentemente da idade. De modo que, os jovens passam por transformações de acordo com seu contexto social, econômico, histórico, biológico, entre outros fatores que são determinantes.

As principais vertentes conceituais nas Ciências Sociais (Antropologia, Ciência política e Sociologia), desenvolveram estudos que tiveram como enfoque principal a socialização. Nesse sentido, muitas foram as contribuições nas discussões. (ZACARIOTTI, 2017).

Os jovens (as juventudes) refletem as transformações sociais e culturais por que passam pela sociedade atual (ZACARIOTTI, 2017). Eles crescem em meio às mudanças que vão ocorrendo cada vez de forma mais rápida, constituem-se e se redefinem 
continuamente, num contexto de liquidez e fluidez, mas com referências ainda sólidas porque nossas instituições, nossos valores e modos de fazer centrados em um pensamento tradicional. Investigar as juventudes em suas relações no desencadeamento desses processos sociais tem sido o desafio de muitos pesquisadores.

Zacariotti (2017), usa o termo juventude no plural, seguindo a linha de pesquisadores que caminham pelo terreno do múltiplo, envolvendo aspectos socioculturais, econômicos-geográficos que falam não de uma juventude, mas de juventudes.

O estudo traz uma base conceitual no discernimento sobre a juventude, onde permiti observar e compreender a cronologia humana, os comportamentos, os desejos, as vontades e a vida social, introduzindo essas questões no campo educacional, pontuando o que é ser jovem.

De acordo com Zacariotti (2017), sua pesquisa sobre juventude faz referências a alguns teóricos que estudam também a temática como: Michel Maffesoli, Edgar Morin e Pierre Bourdieu, que veem a juventude como um campo em desenvolvimento, cheio de controvérsias que busca sua conceituação. Nesse sentido os pensamentos dos estudiosos convergem com a linha de pensamento de Marluce Zacariotti (2017). A juventude não impõe idade e sim as características que desenvolvem em cada sujeito que cria suas identificações. "A juventude é apenas uma palavra, pois, na realidade, existem várias ou pelo menos duas juventudes, a burguesa e a das classes populares, que tem entre si suas diferenças cruciais, em todos os setores de suas vidas”. (Sperandio apud Bourdieu (1983, p.708).

Ao utilizar o termo juventude para falar de jovens como se fossem uma unidade social, um grupo constituído, dotado de interesses comuns e relaciona esses interesses a uma idade biologicamente definida, para ele é uma manipulação evidente e um formidável abuso da linguagem.

Dayrell (2007), faz a leitura de uma juventude com acesso à escola, trazendo alguns apontamentos de insucesso educacional fracasso e desinteresse da juventude com a escola, a desmotivação por parte dos jovens e por falta de um planejamento pedagógico motivador.

De acordo com o auto, ao buscar compreender essa realidade, um primeiro passo é constatar que, a relação da juventude com a escola não se explica mesma: o problema não e, nem apenas aos jovens, nem apenas à escola, como as análises lineares tendem a concebe. (DAYRELL, 2007, p.IIo6).

Entender sobre a juventude é partir da problematização juvenil atual, suas culturas, suas demandas e necessidades próprias. Trata-se de compreender suas práticas e símbolos como manifestação de um novo ser jovem, expressão das mutações ocorrida nos processos de socialização, que coloca em questão o sistema educativo, suas ofertas e as posturas pedagógica que lhes informam Dayrell, (2007, p.1107).

Assim, entendemos que há uma demanda dos jovens no acesso ao Ensino Médio que é existencial, igualmente, é notável uma exigência na reformulação da oferta desse ensino, no sentido de atender aos anseios dessa juventude.

Apesar dos avanços legais na esfera da garantia de direitos para os jovens (I5 a 29 anos) e da criação de instituições governamentais para o desenvolvimento de políticas a eles destinadas instauradas nas últimas duas décadas, é preciso reconhecer que ainda há muitos que se fazer no campo das políticas públicas voltadas para esse grupo, afirma Dayrell e Carrano (2014). 
Assim formalizando o reconhecimento da juventude e seus constitucionais, foi aprovada em 13 de julho de 2010 a emenda constitucional da juventude de no 65 que altera a denominação do Capítulo VII do Título VIII da Constituição Federal e modifica o seu artigo para cuidar dos interesses da juventude que diz;

\begin{abstract}
Art. 227. É dever da família, da sociedade e do Estado assegurar à criança, ao adolescente e ao jovem, com absoluta prioridade, o direito à vida, à saúde, à alimentação, à educação, ao lazer, à profissionalização, à cultura, à dignidade, ao respeito, à liberdade e à convivência familiar e comunitária, além de colocá-los a salvo de toda forma de negligência, discriminação, exploração, violência, crueldade e opressão. (Planalto, EC/2oro).
\end{abstract}

Nesse processo para entender o ser jovem ou trazer uma definição mais aproximada, foi criado o Estatuto da juventude pela Lei ${ }^{\circ}{ }_{12.852}$, de 5 de agosto de 2013, no qual reforça a identificação desse grupo, garantido políticas públicas que atendam a juventude em diversas áreas sociais e destacando a educação como umas das prioridades de acesso.

De uma formal geral, é possível afirmar que a juventude representa um grupo geracional e que o Ensino Médio constitui uma etapa da escolarização que coincide com um período da vida dos jovens, geralmente entre i4 e 18 anos afirma Weller, (2014). Como estamos tratando do conceito de juventude, os horizontes se abrem é importante compreendermos que não se trata de uma prorrogação da infância ou de fazer transitório para a vida adulta, como já discutido por Juarez Dayrell (2012).

Assim, de acordo com Weller (2014), o Ensino Médio também não pode ser pensado como extensão do Ensino Fundamental nem unicamente como transitório ou preparatório para o que virá após a conclusão e obtenção do Diploma. Nesse sentido por coincidir com o período durante o qual se espera que o jovem desenvolva projetos de futuro, de certa forma essa transição é necessária para viabilizar esses projetos na escola de Ensino Médio.

Na perspectiva de Dayrrell, "para os jovens, a escola e o trabalho são projetos que se superpõem ou poderão sofrer ênfases diversas, de acordo com o momento do ciclo de vida e as condições sociais que lhes permitam a viver a condição juvenil”. (2007, p.IIog).

Assim, Dayrrel (2007) tem a compreensão de que no Brasil, a juventude não pode ser caracterizada pela moratória em relação ao trabalho, como é comum nos países europeus. Ao contrário, para grande parcela de jovens, a condição juvenil só é vivenciada porque trabalham, garantindo o mínimo de recursos para o lazer, o namoro ou o consumo.

De certo modo, observa que, a juventude procura as tecnologias como um meio de se comunicar com o mundo, não importa a posição social. Os meios tecnológicos entre os instrumentos mais utilizados por esses jovens pois permitem essa aproximação.

Pode-se dizer que, a tensão entre ser aluno e ser jovem, se manifesta também na relação com o conhecimento e os processos de ensino e aprendizagem, (DAYREL, 2007). Pensar a educação para a juventude no ensino médio é pensar além dos conteúdos, é ter uma visão de futuro, buscar estratégias para provocar interesse dos jovens pela educação e ouvi-los.

O tempo e o espaço, essas diferentes dimensões da condição juvenil, são condicionadas pelo espaço onde são construídas, que passa a ter sentidos próprios, transformando-se em lugar, espaço do fluir da vida, do vivido, sendo o suporte e mediação das relações sociais, investido de sentidos próprios, além de ser a 
ancoragem da memória, tanto individual quanto coletiva. (DAYRELL, 2009, p.21).

Dessa maneira, tendo em vista os avanços das tecnologias, a juventude instiga a escola a reformular o modelo de ensino no século XXI, tornando atraente esse espaço de formação, e tendo o sistema tecnológico como meio de acesso à educação.

\section{Uso das Tecnologias na Educação no Ensino Médio em Escolas no Tocantins}

O Ministério da Educação (MEC), juntamente com o Conselho Nacional de Educação (CNE) e a Câmara da Educação Básica (CEB), atualiza as Diretrizes Curriculares Nacionais para o Ensino Médio (RESOLUÇÃO $\mathrm{n}^{\mathrm{o}}$ 3, DE 2I DE NOVEMBRO DE 2018). De acordo com esse documento, no Art. 80, Inciso II, as propostas curriculares do ensino médio devem garantir ações que promovam:

b) cultura e linguagens digitais, pensamento computacional, a compreensão do significado da ciência, das letras e das artes, das tecnologias da informação, da matemática, bem como a possibilidade de protagonismo dos estudantes para a autoria e produção de inovação. (BRASIL, 2018).

A inclusão e utilização das tecnologias na educação são uma realidade, principalmente se observarmos as estratégias para a meta 7 do Plano Nacional de Educação (PNE, 2014). Mas, como afirmam Júnior e Zacariotti (2020, p. 266), "é importante entender o que as tecnologias da informação e comunicação representam para as novas perspectivas da educação". Nesse sentido, escolas e professores precisam se preparar para se adaptarem a essa nova realidade com propostas pedagógicas e metodológicas de inclusão e valorização da cultura digital. Afinal, como constatou Dioginis et al. (2015, p. II6I), “[...] as disciplinas que se utilizam das novas tecnologias possibilitam melhor compreensão do conteúdo, provocam o interesse e estimulam a curiosidade".

De acordo com o PNE (2014-2024), o desafio é a execução, para que sejam cumpridas as vinte metas, a partir de suas 254 estratégias. Assim, como cada estado do Brasil possui suas particularidades sociais, geográficas e econômicas, fica a cargo destes a construção do seu Plano Estadual de Educação (PEE) para um período de Io anos (20152025), em consonância com o PNE.

Este artigo tem como objetivo principal levantar dados e analisar o andamento e a execução das metas do PNE relacionadas ao uso de tecnologias na educação no ensino médio, direcionando seu olhar para o atual contexto do estado do Tocantins. A metodologia foi pautada nas revisões bibliográfica e documental, combinadas com a realização de uma pesquisa qualitativa através da aplicação de um questionário com dez questões abertas a diretores de três escolas (duas em Paraíso e uma em Gurupi) da rede estadual de ensino do Tocantins. Esses respondentes, uma mulher e dois homens, foram aqui denominamos respectivamente por Di, $D_{2}$ e $D_{3}$. Após a coleta, os dados foram organizados e analisados, levando-se em conta o objetivo da pesquisa, conforme detalhado a seguir.

Com uma média de idade de 49,33 anos, os diretores todos são efetivos e possuem uma significativa experiência na educação, aproximadamente 24,66 anos. No entanto, existe uma disparidade entre o tempo de exercício na direção: enquanto $\mathrm{D}_{2}$ tem apenas um ano no cargo, $\mathrm{D}_{3}$ tem dezessete anos e $\mathrm{D}_{\mathrm{I}}$ tem três anos na função. 
A parte inicial da pesquisa buscava saber sobre possíveis encontros de formação para análise e discussão das metas do PNE, com foco naquelas relacionadas às modalidades de ensino ofertadas na escola. O que se constatou é que dois terços dessas escolas já haviam realizado e que pretendiam dar continuidade a esses estudos ( $D_{1}$ e $\mathrm{D}_{3}$ ). A outra pretende desenvolver o primeiro encontro sobre o tema no decorrer de 2021. Levando-se em conta o decênio para execução dessas metas (2014-2024), algumas unidades escolares se mostram mais atrasadas, tendo em vista que o estudo e planejamento são essenciais para a implementação de ações que visam o cumprimento da legislação.

Os diretores pesquisados foram unânimes ao afirmarem que a Secretaria Estadual de Educação do Tocantins (SEDUC/TO) orienta e incentiva o uso das tecnologias, porém, observou-se opiniões bem distintas quanto aos investimentos. Enquanto Di destaca "[...] que há tempos temos salas de lousa digital, laboratórios de informática em pleno funcionamento, salas de vídeo ambiente, bem como kits multimídia”, contrasta com as realidades vividas por $\mathrm{D}_{2}$ e $\mathrm{D}_{3}$ que ressaltam a falta de recursos. $\mathrm{D}_{3}$, referindo-se à SEDUC, mencionou que: "[...] até o momento não disponibilizou condições para que possamos utilizar de forma satisfatória essas tecnologias. A escola não dispõe de recursos suficientes para aquisição de tais ferramentas". D2 acrescentou que: "[...] a escola ainda não recebeu nenhum equipamento, recebemos um recurso que foi utilizado em pequenos reparos de equipamentos e melhoria no sinal da internet”.

Nesse sentido, é preciso questionar o cumprimento da meta 20 do PNE, que trata dos recursos financeiros, bem como uma análise crítica acerca das responsabilidades, prioridades e distribuição desses investimentos, a fim de garantir minimamente os recursos necessários para a atualização das escolas no que tange às tecnologias educacionais. Afinal, como afirmam Araújo e Pinho (2020, p. 298):

[...] existem milhares de maneiras de integração de tecnologias no contexto educacional, o que falta são as condições concretas, de uma realidade facetada pela escassez de recursos financeiros e tecnológicos em quantidade suficiente para que o acesso a equipamentos, e a conectividade em qualidade suficiente.

Um fato detectado na pesquisa é que existem diferenças consideráveis de uma escola para outra quando se trata do acervo tecnológico. Para a diretora Di, na sua escola ele é considerado bom. E afirma: "Temos recursos tecnológicos diversificados que passam por revisões quando necessário". Já para $\mathrm{D}_{2}$, seu acervo é regular. Enquanto para $\mathrm{D}_{3}$, seu acervo é ruim e justifica: "Não existe ferramenta suficiente e que as que existem estão sucateadas". Entre os recursos mais utilizados nessas escolas indicam-se: o projetor (Data show), TVs e computadores. Com destaque para lousa digital e Smartphone citados por Di e $\mathrm{D}_{2}$ respectivamente.

Segundo os diretores, a capacitação dos professores quanto ao uso das tecnologias na educação vem ocorrendo através de orientações e formações advindas principalmente da SEDUC/TO. Isso faz sentido, tendo em vista que " [...] primeiramente os profissionais precisam estar seguros no uso destas mobilidades tecnológicas, para que os alunos possam usufruir destes equipamentos..., com objetivos claros de 'ensino aprendizagem'...". (CHIOFI e OLIVEIRA, 2014. p. 334).

Apesar das dificuldades apontadas por cada diretor, todos classificaram como positiva e importante a elaboração, a estruturação, o planejamento e a execução das metas 
do PNE relacionadas às tecnologias na educação, mas apresentaram algumas ressalvas, que podem ser bem compreendidas na fala do diretor $\mathrm{D}_{2}$ :

Vejo como um salto importante para educação do nosso país enquanto proposta,
no entanto, ainda falta muito para se concretizar. É preciso transformar as ideias
em mobilização como forma de materializar as propostas, é importante que cada
um cumpra seu papel nesse contexto, principalmente o poder público com
recursos financeiros e humanos como forma de garantia e implantação (D2, 202I).

Os diretores foram coesos ao afirmarem que devido à pandemia causada pelo coronavírus, houve certa urgência na utilização das tecnologias na educação, fato esse que contribuiu com o aceleramento quanto ao cumprimento das metas relacionadas a essa temática. Entretanto, como afirma $\mathrm{D}_{2}$ : “[...] não vimos nenhum investimento significativo para esse atendimento, em muitas situações os alunos e professores tiveram que buscar caminhos sozinhos [...]”.

Apesar disso, há certo otimismo entre esses diretores para o ano de 202I nas perspectivas do planejamento, da execução e do financiamento direcionados ao uso das tecnologias na educação. Considerando o prazo limite de $2024, \mathrm{D}_{3}$ responde que: "Esperamos que as entidades responsáveis pela execução do financiamento direcionados as tecnologias, disponha os recursos suficientes para que até o final no prazo de execução estejam todos disponíveis".

Por fim, em relação às metas propostas no Plano Nacional de Educação em relação ao uso das tecnologias na educação, apenas Di respondeu que já está em andamento; os outros dois diretores disseram que estão na perspectiva de serem cumpridas, aguardando principalmente recursos para aquisição das ferramentas tecnológicas.

No geral, os participantes afirmam que o uso das tecnologias são desafios e que estão tentando avançar, por meio das ferramentas disponíveis, fazendo melhorias e realizando novas aquisições dentro das possibilidades. Esse pode ser o caminho, afinal, "ao utilizar a tecnologia a favor da educação de qualidade, contribuímos na promoção do desenvolvimento socioeducativo, além da socialização do saber e da informação pelo aluno". (CHIOFI e OLIVEIRA, 2014, p. 333-334).

Entre as principais dificuldades apontadas em relação às metas propostas, de acordo com os diretores entrevistados, estão: a falta de recursos financeiros, a resistência de alguns professores a mudanças de estratégias de trabalho e a falta de conectividade dos alunos. Mesmo assim,

\footnotetext{
a educação, apesar de não conseguir acompanhar par a par os avanços das tecnologias digitais, passa pouco a pouco a utilizá-las, quer seja por meio de programas oficiais, quer seja por meio de ações informais tanto de professores como de alunos. (BRIZOLA e ALONSO, 2017, p. 135).
}

Apesar dos esforços de professores, diretores, pais e alunos, a utilização das tecnologias na educação ainda caminha em passos curtos, principalmente devido ao pouco investimento nesse setor. Com isso, pensando no prazo final do PNE em vigência, fica a expectativa de que neste e nos próximos anos haja, por parte do poder público, o provimento dos recursos essenciais para a implementação e execução das metas educacionais ligadas a tecnologia, observando a capacitação de professores e a formação dos alunos. 


\section{CONSIDERAÇÕES FINAIS}

De acordo com o próprio documento elaborado, o PNE busca trazer significativos avanços para a educação brasileira. No entanto, considerando seu período de vigência e o cenário atual - já percorridos mais de 50\% dos dez anos, o que observamos em alguns casos são realidades bem distintas do proposto.

Tendo como base os resultados da pesquisa, podemos dizer que as metas do PNE relacionadas ao uso das tecnologias na educação ainda precisam avançar consideravelmente no Tocantins. Em algumas escolas faltam equipamentos e os poucos que existem estão em péssimas condições. A reclamação da falta de recursos para investimentos em tecnologia é comum entre os diretores. Essas dificuldades apontadas comprometem o desenvolvimento das metas com estratégias tecnológicas e retarda os possíveis avanços educacionais.

Mesmo que não seja nas mesmas proporções, devido à grande desigualdade social que assola nosso país, as tecnologias fazem parte do nosso cotidiano, se não em casa, nas ruas, no trabalho e na escola. Nossas juventudes que compõem o ensino médio vivem mais intensamente essa realidade. E a educação precisa urgentemente se atualizar, utilizando-se dos meios tecnológicos disponíveis, com novas didáticas e novas formas de se comunicar e interagir com esses estudantes.

Assim, seguindo na linha do pensamento de um dos diretores entrevistados, para o cumprimento das metas relacionadas às tecnologias na educação é preciso que todos façam sua parte: os governos (Federal e Estadual), garantindo os recursos necessários para os investimentos em equipamentos e capacitações; as escolas, atuando no planejamento e execução das ações; e os professores, desenvolvendo e aplicando práticas pedagógicas inovadoras e de integração. Só assim, poderemos almejar, ao término desse decênio do PNE, melhorias significativas no processo de ensino e aprendizagem, na qual as tecnologias sejam verdadeiras parceiras.

\section{REFERÊNCIAS}

ARAUJO, Deusirene Magalhães de; PINHO, Maria José de. Tecnologias digitais na educação tocantinense: desafios e possibilidades na criação de redes de aprendizagem. Humanidades \& Inovação, v. 7, n. 18, p. 287-300, 2020.

BRASIL. Conselho Nacional de Educação. Câmara de Educação Básica. Resolução no 3, de 2I de novembro de 2018. Atualiza as Diretrizes Curriculares Nacionais para o Ensino Médio. Brasília, DF, 2018. Disponível em: 〈https://www.in.gov.br/materia//asset_publisher/KujrwoTZC2Mb/content/id/51281622>. Acesso em: 8 jan. 2021.

BRASIL. Constituição da República Federativa do Brasil de I988.

Disponível em: 〈http://www.planalto.gov.br/ccivil_03/constituicao/constituicao.htm〉

Acesso em: 8 jan. 202I.

BRASIL. Lei no 12.852 de 5 de agosto de 2013. Institui o Estatuto da Juventude e dispõe sobre os direitos dos jovens, os princípios e diretrizes das políticas públicas de juventude e o Sistema Nacional de Juventude - SINAJUVE. Brasília, DF, 2013. Disponível em: 
〈http://www.planalto.gov.br/ccivil_03/_ato2orI-2014/2013/lei/li2852.htm>. Acesso em: 5 jan. 202I.

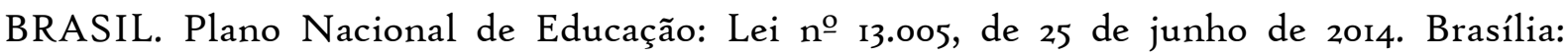
Câmara dos Deputados, Edições Câmara, 2014.

BRIZOLA, Jairo; ALONSO, Kátia Morosov. Tecnologias e educação: o uso das TIC no ensino médio. Revista de Educação do Vale do Arinos - RELVA, LOCAL, v. 4, n. I, p. X$\mathrm{X}$, mês 2017 .

CHIOFI, Luiz Carlos; OLIVEIRA, Marta Regina Furlan de. O uso das tecnologias educacionais como ferramenta didática no processo de ensino e aprendizagem. Londrina: UEL, 2014 .

DAYRELL, Juarez; CARRANO, Paulo. Juventude e Ensino Médio: Quem é este aluno que chega a escola. In Org. Dayrell, Carrano e Maia. Editora UFMG, Belo Horizonte,2014.

DAYRELL, Juarez. A escola "faz" as juventudes? Reflexões em torno da socialização juvenil. Educ. Soc [online], Campinas, vol. 28, N. Ioo - Especial, p. IIO5-I128. Disponível em: 〈https://www.cedes.unicamp.br/publicacoes/20〉. Acesso em: 20 dez. 2020.

DIOGINIS, M. L. et al. As novas tecnologias no processo de ensino aprendizagem. In: Colloquium humanarum. Presidente Prudente, vol.12, n. Especial, out/2015.

MORAIS JÚNIOR, Wellington Holanda; ZACARIOTTI, Marluce. Da sala de aula ao Youtube: as juventudes e seus modos de aprender em (na) rede. Humanidades \& Inovação, LOCAL, v. 7, n. 6, p. 264-275, 2020.

Resolução CNE/CEB 3/2018. Diário Oficial da União, Brasília, 22 de novembro de 2018, Seção I, pp. 21-24.

SPERANDIO, Amábile. E. A. A participação sociopolítica dos jovens durante a Ditadura Militar no Brasil. In: Semana de História: palavra e destino comum. São Paulo, 2015. Anais eletrônico. São Paulo: Unesp 2015, p. 706 - 718. Disponível: < http://www2.assis.unesp.br/fcl/livro/anais_xxxi_semana_historia/files/assets/common/ downloads/publication.pdf> Acesso em: 5 jan. 202I.

TOCANTINS. Lei no 2.977 de 8 de julho de 2015. Aprova o Plano Estadual de Educação do Tocantins - PEE/TO (2015-2025), e adota outras providências. Palmas, TO, 2015. Disponível em: <https://www.to.gov.br/seduc/plano-estadual-de-educacaopee/2lushdwcyig9> Acesso em: io jan. 2021.

WELlER, W. TITULO DO CAPITULO. In: DAYRELL, J.; CARRANO, P. C.; MAIA, C. L. Juventude e o Ensino Médio. Editora UFMG, Belo Horizonte, 2014. p. 136.

ZACARIOTTI, M. (In) visibilidades das juventudes Pós-modernas: trilhas estéticas na cibercultura. Curitiba: CRV, 2017. 